\title{
THE ALIGNMENT OF SOIL'S CONDITIONS FOR PLANT'S DEVELOPMENT DURING MICROBIAL DESTRUCTION OF PLANT'S RESIDUES BY MICROBIAL PREPARATIONS
}

\author{
O.V. SVIRIDOVA', N.I. VOROBYOV'1, N.A. PROVOROV'1, O.V. ORLOVA', \\ I.V. RUSAKOVA ${ }^{2}$, E.E. ANDRONOV 1 , V.N. PISHCHIK ${ }^{3}$, A.A. POPOV ${ }^{1}$, \\ Yu.V. KRUGLOV1
}

\begin{abstract}
${ }^{1}$ All-Russian Research Institute for Agricultural Microbiology, Federal Agency of Scientific Organizations, 3, sh. Podbel'skogo, St. Petersburg, 196608 Russia, e-mail Nik.IvanVorobyov@yandex.ru;

2All-Russian Research Institute for Organic Fertilizers and Peat, Federal Agency of Scientific Organizations, 2, ul. Pryanishnikova., pos. Vyatkino, Sudogodskii Region, Vladimir Province, Russia 601390, e-mail rusakova.iv@yandex.ru; ${ }^{3}$ Agrophysical Research Institute, Federal Agency of Scientific Organizations, 14, Grazhdanskii pr., St. Petersburg, Russia 195220, e-mail veronica-bio@rambler.ru

Acknowledgements:

The equipment of ARRIAM Center for Genome Technologies, Proteomics and Cell Biology (St. Petersburg) was used. Supported by Russian Science Foundation (grant № 14-26-00094)

Received November 20, 2015
\end{abstract}

\section{Abstract}

Modern agriculture is developing in the direction of producing consistently high yields and high quality seed production. In this regard, the precision agricultural technologies are develop for the leveling a soil conditions. Individual phenotypic characteristics of plant are determined by the local soil conditions near their root's systems. As a result, the variance of plant's height is dependent on the spatial distribution of energy resources and nutrients in the soil. The variance of plant's height restricted to the genetic norm for this characteristic and it can been reduced when a soil conditions are leveled. In experiments with planting alfalfa was been shown, that the variance of plant's mass may decrease with an increase in the efficiency of plant-microbial symbiosis. Perhaps the plantmicrobial symbiosis is able to level a soil conditions and selectively stimulate the plants by using of the microbial metabolites. We assume that the effect of microbiological leveling soil conditions (MLSC) may be observed during destruction of plant's residues using microbial preparation. Previously, MLSC effect has not studied. Therefore, these theoretical and experimental researches are new. In addition, we have obtained new practically important results thanks to the use of the original fractal analysis of molecular-genetic data of the soil microbial community. The goal of this work was experimental and theoretical study of MPSC effect arising after destruction of plant's residues with the using of the microbial preparations, which was been developed in the All-Russian Research Institute of Agricultural Microbiology. To achieve this goal were used the data of two experiments. In the first experiment, the variances of the barley plant's height were been investigated after the destruction of plant residues using a microbial preparation Barkon. Out the second experiment used data of the molecular-genetic analysis of soil microbial communities after the destruction of plant's residues using three microbial preparations: Barkon, Bags and Omug. The preparation Barkon contains the consortium of bacteria and fungi; Bugs is a consortium of cellulolytic organisms, derived from biologically active soil; Omug is the microbial fertilizer obtained after biotechnological processing of poultry manure. The functional activity of microbial networks arising during the destruction of plant's residues with using of microbial preparations was been studied using fractal analysis of molecular genetic data of microbial communities in soil. With using of the fractal analysis was been obtained the fractal taxonomic portrait of microbial communities and the index of the functional efficiency of microbial network formations, which were formed during destruction of plant's residues. The first experiment showed that the using of preparations for the destruction of plant's residues leads to a gradual leveling of the soil's conditions and to reducing of the variance of plant's heights, which were been grown on these soils. Without these preparations, the dispersion of plant's heights increases with each successive year. From this, it follows that these preparations may initiate the effective microbial networks that are able to save the energy resources and the nutrients distributing them evenly in the soil. The moleculargenetic data from second experiment confirmed that the functional efficiency of the microbial networks after using preparations significantly increases due to better organization of destructive processes. The results of this study suggest that the destruction of plant's residues by using of the special preparations is a necessary and effective complement of the modern precision agro technologies. Thus, the microbial 
preparations for destruction plant's residues start processes which lead to the restoration of the required level of energy resources and nutrients in the soil, to the leveling of resources in soil's space, to the increasing the stability of yields and to the improving the quality of plant's products.

Keywords: the destruction of plant's residues with using of the microbial preparations; the microbial destructive communities in the soil; the dispersion of the individual heights of plants, the fractal-taxonomic portrait of the microbial community; the index of the functional efficiency of microbial networks

Modern agriculture is developing toward sustainable high yields and high quality seed production. In this regard, the precision agricultural technologies for leveling soil conditions are being developed [1-5].

The growing season of plants, starting from seed germination, depends on the local soil conditions in a small area surrounding the seeds and roots. Each plant is characterized by individual parameters of stem height, the number of vegetative organs, the weight of the above-ground and root parts, etc. As a result, there is dispersion (variability) of quantitative phenotypic traits in the populations. On the top it is limited to the allowable normal plant response to changes in the environmental factors [6], and may decrease in the setting of the soil conditions leveling [7-10]. A decrease in the variability of phenotypic traits of plants was found in the 3-year experiments in alfalfa (Medicago sativa) [11]. Each year, the ratio of genotypic and phenotypic components of the plant biomass dispersion changed. The observed increase in the variety-strain (genotypic) component and a decrease in a random (phenotypic) one may have been caused by the leveling of the soil conditions as a result of increased efficiency of microbial-plant symbiosis, although it could also be the result of targeted stimulation with microbial metabolites $[12,13]$ in those plants in the population, which were in a less favorable environment compared to the remaining plants.

We assume that the effect of microbiological leveling of soil conditions (MLSC) is associated with the destruction of plant residues by microbial-based products. In this case, there is a selective accumulation of nutrient resources by microorganisms in soil microniches which initially lack them. MLSC is possibly a consequence of the diffusion of low molecular weight nutrients, resulted from the plant residue degradation, to areas with a low content of nutrient resources. It is obvious that in such leveled soils plants must demonstrate a lower variability of quantitative phenotypic traits and the high yield quality [14].

To date, the question whether the MLSC processes are affected by microbial products that cause the destruction of plant residues in the soil in the pregrowing period of the year (without plants), has not been investigated. We are the first to describe these effects, having received significant for the practical application results by using a genuine fractal analysis of molecular genetic frequency data for soil microbial communities, and the coefficient of variation of the individual heights of plants grown on the respective soils.

The aim of this work was an experimental and theoretical study of the effect of microbiological leveling of the soil conditions using microbial-based products which initiate the functioning of microbial networks in soil.

Techniques. In the experiment 1 (carried out in 2011-2014), we used an experimental sample of a microbial-based product Barkon for humification of plant residues (developed by the All-Russian Research Institute for Agricultural Microbiology, ARRIAM), which consisted of a consortium of bacteria and fungi [15]. In pots containing the sod-podzolic soil $\left(3.5 \mathrm{~kg}, \mathrm{C}_{\text {hum }} 2.0 \%, \mathrm{~N}_{\text {tot }} 0.19 \%\right.$, $\mathrm{pH}_{\text {sol }} 5.6$ ), barley straw (BS) was laid at a depth of $0-3 \mathrm{~cm}$. This experiment included the following options: 1 - control (without addition of BS), 2 - addition of BS without inoculation of Barkon, 3 - addition of BS, inoculated with Barkon (1 ml/10 g of straw). The crushed BS (air-dry weight $10 \mathrm{~g}$ per pot) in 
the options 2 and 3 was introduced into pot 3 times, i.e. in autumn of 2011, 2012 and 2013. There were 4 pots used in each option. Fertilizers were not added in the pot during the experiment. Barley plants (Hordeum L.) were planted into the pots in the spring 2012, 2013 and 2014 (30 pcs per pot), and at the end of the growing season (autumn 2012, 2013 and 2014) the height of the aboveground parts of plants (100-120 pcs per experiment option) was measured. The data were processed using the analysis of variance [16], and the coefficient of variation of this phenotypic trait per each experiment option was calculated.

In experiment 2, molecular genetic data on the microbial communities were used to study the network organization of microorganisms, which constituted the basis of the biologicals for the destruction of cereal straw [17]. Per $1 \mathrm{~kg}$ of cultivated sod-podzolic soil $\left(\mathrm{C}_{\text {hum }} 4.02 \% ; \mathrm{N}_{\text {tot }} 0.316 \% ; \mathrm{pH}_{\text {sol }} 5.63\right)$ in each pot, $3 \mathrm{~g}$ of crushed rye straw (RS) was added in three ways, i.e. either superficially or laying down the surface at a depth of $0-3 \mathrm{~cm}$ and $9-12 \mathrm{~cm}$. To accelerate the decomposition, the straw was treated with Bags, Barkon and Omug, according to the the developers' recommendations (ARRIAM). Bags is a consortium of cellulosolytic microorganisms based on the biologically active substrate [18], and Omug is a microbial fertilizer obtained after biotechnological processing of poultry manure [19].

On day 60 , the molecular genetic analysis of 12 soil samples was performed using a standard technique [19] and a CEQ 8000 genetic analysis system (Beckman Coulter International S.A., Switzerland). Data on the frequency of occurrence of operational taxonomic units (OTE) in the soil samples were subjected to a modified fractal analysis [21-26] in order to obtain information about the characteristics of the resulting microbial network formations. Taxonomic data were not used in the study. Data on the taxonomic analysis of the same data were presented earlier [17].

Results. In the experiment 1 (options 1 and 2), the coefficient of variation of plant heights (VPH) in barley plants increased from $1^{\text {st }}$ to $3^{\text {rd }}$ year of observation (Table 1). The total amount of nutrient resources in soil was likely to decrease, thereby increasing the variability of the soil conditions and individual plant heights.

1. The coefficient of variation of plant heights (VPH) in barley plants when grown on soil with barley straw (BS) added as plant residues, and depending on the inoculation of the microbial-based product Barkon

\begin{tabular}{l|c|c}
\hline \multicolumn{1}{c|}{ Option } & Year & Coefficient VPH, \% \\
\hline Control (without addition & 2012 & 19.8 \\
of BS) & 2013 & 25.5 \\
& 2014 & 27.0 \\
Adding BS without inocula- & 2012 & 13.2 \\
tion of Barkcon & 2013 & 14.9 \\
& 2014 & 16.3 \\
Adding BS with inocula- & 2012 & 17.1 \\
tion of Barkon & 2013 & 14.5 \\
& 2014 & 16.0 \\
\multicolumn{1}{c}{ Confidence interval } & & \pm 0.2 \\
\hline
\end{tabular}

In the option 3 , the coefficient of VPH over the years, on the contrary, decreased (see Table 1). This suggests that using a microbial-based product led to a gradual increase in the efficiency of soil destructive microbial community. The accumulation of nutrient resources for plants and leveling of soil conditions can take several years [27].

It is probable that low molecular weight nutrients are formed during this period, diffusing into microniches with their low concentration, which might also lead to fading initial differences between the microniches.

Microbiological degradation of plant residues can be represented as a gradual division of organic molecules into a growing number of fragments of decreasing size. As a mathematical object displaying the destruction of the molecules, it is proposed to use the power series of non-integral numbers, belonging to 
the fractal numerical series [28, 29]. For example, a sequence $(1,1 / 2,1 / 4,1 / 8, \ldots)$ is a fractal set as it is formed obeying the rule fixed for all numbers in the set: each following number in a series is twice as little as the previous one.

Numbers from fractal series can be roughly compared with the size of fragments of molecules. Then the position in the fractal series will mean a number of the destruction stage, and the current number of a series will indicate the size of fragments of molecules, which are subjected to destruction at an appropriate stage. Actual degradation processes take place with the change of molecular fragmentation rules. At some stages the number of fragments can be doubled, in other - tripled, i.e. we assume that the microbiological degradation processes are multifractal [30-34].

Our studies have shown that for the fractal series-based mathematical modeling of complex destructive processes of organic molecules it is sufficient to use only the first three members of the fractal series. This restriction considerably simplifies the identification of complex destructive processes with unknown beforehand rules of fragmentation and number of stages of destruction.

We believe that the destruction of organic molecules of plant residues by microorganisms is carried out along with the formation of multifractal network microorganism structures $[35,36]$. Moreover, the process takes place with the involvement of the required number of microorganisms which is proportional to the number of fragments undergoing degradation. Such an assumption allows for fractal analysis of microbiological destruction processes based on the OTU frequencies of occurrence using the following mathematical rule that binds the frequencies of three OTUs:

$$
\frac{\ln \left(p_{k}\right)}{\ln \left(p_{\max }\right)}=\frac{\ln \left(p_{0}\right)}{\ln \left(p_{\max }\right)}+a \cdot k,
$$

where $p_{k}$ is frequency of occurrence of microorganisms of the $k$ OUT which perform the destruction of organic molecules at the $k$ stage $(k=0,1,2) ; p_{\max }$ is frequency of occurrence of the microorganisms of the dominant OTU in the soil community; $a$ is a constant coefficient, a fractal index of the primary destructive set of microorganisms (PDS).

The logarithmic dependence (1) enables to isolate and identify three OTUs combined into the PDS, in which the microorganisms carry out destruction of organic molecules obeying a single rule of fragmentation. To detect several PDSs in microbial communities, it is required to try all possible combinations by three OTUs and select those which satisfy the following equations:

$$
\left\{\begin{array}{l}
\frac{\ln \left(p_{1}\right)}{\ln \left(p_{\max }\right)}=\frac{\ln \left(p_{0}\right)}{\ln \left(p_{\max }\right)}+a \\
\frac{\ln \left(p_{2}\right)}{\ln \left(p_{\max }\right)}=\frac{\ln \left(p_{1}\right)}{\ln \left(p_{\max }\right)}+a( \pm d)
\end{array},\right.
$$

where $1>p_{0}>p_{1}>p_{2}$ are frequencies of occurrence of OTUs, forming the PDS, the microorganisms of which carry out the destruction of organic molecules in three steps obeying a single rule of fragmentation; $0 \leq d \leq 0,01$ is a margin of error of the fractal PDS index to identify it, which depends on the accuracy of measuring the OTU frequency parameters.

The figure (A) shows an ordered series of normalized logarithms of frequencies of 22 OTUs from the experiment 2 (the option with the Barkon use and location of inoculated RS on the soil surface). As an example, three OTUs, the frequencies of which satisfy the equations (2), are shown. Consequently, the corresponding microorganisms were involved in the degradation of plant residues, obeying a single rule of fragmentation, and formed the PDS. 

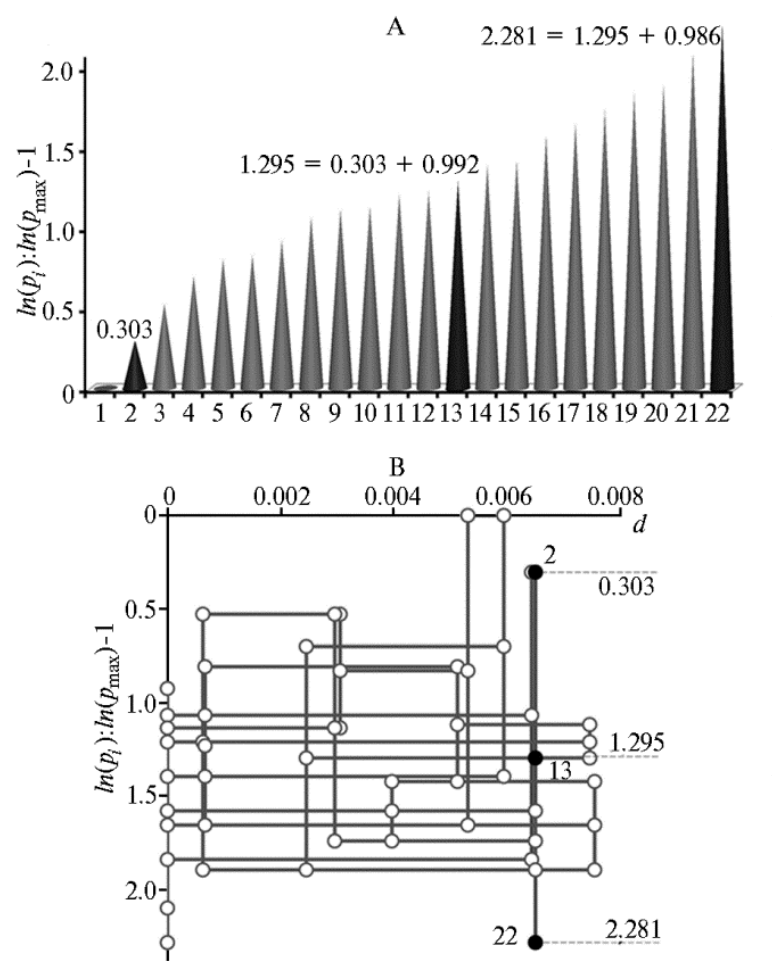

The ordered series of the frequencies of individual taxonomic units (OTE), identified by molecular genetic methods (A), and the fractal taxonomic profile of the soil bacterial community with the superficial location of the rye straw inoculated with the microbial-based product Barkon (B): 1-22 - serial numbers of OTUs, $d-$ the error of the fractal PDS (primary destructive set) index (2); $\ln \left(p_{\max }\right), \ln \left(p_{i}\right)$ - natural logarithms of the OTU frequencies, respectively, with a maximum frequency of occurrence and the serial number $i$ in the series of frequencies. OTU №№ 2, 13, 22 satisfy the equations (2).

PDSs which were formed by 22 OTUs. OTU № 7 and № 22 entered the PDS only once, and all the remaining - two or more times. Consequently, some groups of microorganisms could function simultaneously in several PDSs obeying different rules of the molecular fragmentation. These microorganisms may simultaneously synthesize several enzymes that could lead to a decrease in the rate of synthesis and reduced efficiency of the entire destructive process. We therefore propose to calculate the functional efficiency index of microbial network formations $(\mathrm{ENF})$ using the following formula:

$$
I_{N E T}=\ln \left(N_{M}\right): \ln \left(3 \cdot N_{F}\right) \text {, }
$$

where $I_{N E T}$ is the index of ENF; $N_{M}$ is a total number of OTU which formed the PDS; $N_{F}$ is the number of PDS in the microbial community.

The highest ENF index is 1, and all OTUs are only in one PDS in the microbial community. In other words, such a destructive microbial community operates with maximum specificity (one group of microorganisms is equal to one destructive function).

Table 2 shows the ENF indices describing the efficiency of degradation of plant residues by the soil microbial communities, initiated by microorganisms which are the ingredients of the following products: Bags, Barkon and Omug. In the control, the ENF index appeared to be lower than in other option, i.e. the 
microbiological processes were disorganized and ineffective. The use of microbial-based products significantly increased the efficiency of the microbial communities, which was confirmed by increases in the ENF index values compared to the control and the experimental options without their application.

2. The index of the effective network formation (ENF) of destructive microbial communities in the soil, with the rye straw (RS) laid at different depths, and depending on the inoculation of different biologicals

\begin{tabular}{lccc}
\hline \multicolumn{1}{c}{ Option } & Depth of laying RS into soil, cm & $I_{N E T}$ (the ENF index) (3) \\
\hline Control (without RS) & 0 & 0.634 \\
Laying RS without inoculation with & $0-3$ & 0.662 \\
biologicals & $9-12$ & 0.676 \\
& 0 & 0.700 \\
Laying RS inoculated with Barkon & $0-3$ & 0.746 \\
& $9-12$ & 0.701 \\
Laying of RS inoculated with Bags & 0 & 0.669 \\
& $0-3$ & 0.686 \\
& $9-12$ & 0.689 \\
Laying of RS inoculated with Omug & 0 & 0.669 \\
& $0-3$ & 0.630 \\
Confidence interval & $9-12$ & 0.705 \\
& & 0.753 \\
\end{tabular}

When the straw was laid in the upper layers of the soil, the highest ENF indexes were observed with the use of microbial-based products Barkon and Bags. The development of networks, initiated by these biologicals, occurred with the involvement of aerobic soil microorganisms as suppliers of energy resources [38]. In contrast, the composition of Omug included poultry intestinal microorganisms, i.e. those from the anaerobic environment. When Omug was used, the greatest value of the ENF index was observed in the setting of deep $(9-12 \mathrm{~cm})$ laying of the straw into the soil.

Comparing the data from the experiments 1 and 2, we can state the following. A gradual increase in the functional efficiency of the network destructive microbial formations initiated by the biological was the major reason for the negative trend in the VPH coefficient values by year in the option 3 of experiment 1. The long-term adjustment of the microbial community for the optimum destructive activity may not be only aimed at the destruction of plant residues, but also at restoring the required amount of energy resources and nutrients in the soil, as well as their leveling in the soil area.

Thus, the destruction of plant residues with the help of special microbial-based products can effectively and at lower cost solve problems of leveling the amount of energy resources and nutrients in the soil. In addition, the initiation of destructive microbiological processes contributes to restoring the required amount of energy resources and nutrient content in the soil, enhancing the stability of yields and improving the quality of the obtained plant products.

\section{REFERENCES}

1. Y a k u s e v V.P., Y a k u s h v V.V. Informatsionnoe obespechenie tochnogo zemledeliya [Information support of precision agriculture]. St. Petersburg, 2007 (ISBN 5-86763-181-8) (in Russ.).

2. M c B ratney A., Whela n B., Ancev T., B o u ma J. Future directions of precision agriculture. Precision Agriculture, 2005, 6: 7-23 (doi: 10.1007/s11119-005-0681-8).

3. Zhang X., Shi L., Jia X., S e i e lst ad G., H e lga s o n C. Zone mapping application for precision-farming: A decision support tool for variable rate application. Precision Agriculture, 2010, 11(2): 103-114 (doi: 10.1007/s11119-009-9130-4).

4. Gebbers R., Ad a m chuk V.I. Precision agriculture and food security. Science, 2010, 327: 828-831 (doi: 10.1126/science.1183899).

5. Nikkilä R., S e ilo ne n I., Koski ne n K. Software architecture for farm management information systems in precision agriculture. Comput. Electron. Agric., 2010, 70(2): 328-336 (doi: 10.1016/j.compag.2009.08.013). 
6. Inge-Vechtomov S.G. Genetika s osnovami selektsii [Genetics and fundamentals of breeding]. St. Petersburg, 2010 (in Russ.).

7. Griffiths A.J.F., Miller J.H., Suzuki D.T., Lewontin R.C., Gelbart W.M. Norm of reaction and phenotypic distribution. An introduction to genetic analysis. NY, 2000 (ISBN 0-7167-3520-2).

8. Avdeev Yu.I., Morozova L.V., Avdeev A.Yu., Kigas h pa e a O.P. Astra-khanskii vestnik ekologicheskogo obrazovaniya, 2014, 28(2): 114-120 (in Russ.).

9. A v d e e v Yu.I. Geneticheskii analiz kolichestvennykh priznakov rastenii [Genetic analysis of quantitative traits in plants]. Astrakhan', 2003 (in Russ.).

10. Guzhov Yu.L., G ne i m A.R. Genetika, 1982, 18(2): 82-99 (in Russ.).

11. Tik ho novi ch I.A., P rov o rov N.A. Simbiozy rastenii i mikroorganizmov: molekulyarnaya genetika agrosistem budushchego [Microbial-plant symbiosis: molecular genetics of prospective agrosystems]. St Petersburg, 2009 (in Russ.).

12. Lugte nberg B.J.J., d e We ge r L.A., B e n n e t t J.W. Microbial stimulation of plant growth and protection from disease. Curr. Opin. Biotech., 1991, 2(3): 457-464 (doi: 10.1016/S09581669(05)80156-9).

13. Mordukhova E.A., Kochetkov V.V., Polikarpova F.Ya., Boronin A.M. Prikladnaya biokhimiya i mikrobiologiya, 1998, 34(3): 287-292 (in Russ.).

14. Z a valin A.A. Biopreparaty, udobreniya $i$ urozhai [Biologicals, chemicals and crop yield]. Moscow, 2005 (in Russ.).

15. Vorob'ev N.I., Sviridova O.V., Popov A.A., Rusakova I.V., Petrov V.B. Sel'skokhozyaistvennaya biologiya [Agricultural Biology], 2011, 3: 88-93 Available http://www.agrobiology.ru/3-2011vorobiev.html. No date (in Russ.).

16. Vor o b'e v N.I., P r o v o r o v N.A., P i s h c h i k V.N., S v i ri d o va O.V. Programma dvukhfaktornogo dispersionnogo analiza biologicheskikh dannykh. Programma zaregistrirovana $\mathrm{v}$ FGU FIPS v otdele registratsii programm dlya EVM № 2014661477 ot 30.10.2014. Svidetel'stvo o gosudarstvennoi registratsii programmy dlya EVM № 2014661477 ot 30.10.2014 [Computer Program for two-factor scheme of dispersion analysis of biological data. State Reg. Cert. № 2014661477. Registered October 30, 2014]. Available http://wwwl.fips.ru/wps/portal/Registers/. No date (in Russ.).

17. Orlova O.V., Andronov E.E., Vorob'ev N.I., Kolodyazhnyi A.YU., Moskalevskaya Yu.P., Patyka N.V., S viridova O.V. Composition and functioning of microbial communities in the decomposition of straw cereals in sod podzolic soil. Agricultural Biology, 2015, 50(3): 305-314 (doi: 10.15389/agrobiology.2015.3.305eng) (In Engl.).

18. K r u g lo v Yu.V., P a ro m e n s k y a L.N. Sel'skokhozyaistvennaya biologiya [Agricultural Biology], 2011, 3: 76-80 Available http://www.agrobiology.ru/3-2011kruglov.html. No date (in Russ.).

19. Ark hip chenko I.A., B arboli na I.I., Deriks P. Doklady Rossel'khozakademii, 1998, 6: 18-19 (in Russ.).

20. B ryuk hanov A.A., N e t rus ov A.I., R ybak K.E. Molekulyarnaya mikrobiologiya [Molecular microbiology]. Moscow, 2012 (ISBN 978-5-211-05486-8) (in Russ.).

21. Vorob'e v N.I., Provorov N.A., S vi ridova O.V. Materialy IV Vserossiiskoi nauchnoprakticheskoi konferentsii «Biologicheskie sistemy: ustoichivost', printsipy i mekhanizmy funktsionirovaniya» [Proc. IV Conf. «Biological systems: sustainability, principles and functioning». Iss. 1]. Nizhnii Tagil, 2012, vypusk 1: 103-106 (in Russ.).

22. Voskresenskaya O.L., Skochilova E.A., Kopylova T.I., Alyabyshe v a E.A., S a rb a e v a E.V. Organizm i sreda: faktorial'naya ekologiya [An organism and its environment - factorial ecology]. Ioshkar-Ola, 2005 (ISBN 5-94808-149-4) (in Russ.).

23. Los a G.A., Merlini D., No n ne $\mathrm{nmacher}$ T.F., We ibel E.R. Fractals in biology and medicine. Vol. IV. Berlin, 2005.

24. A k b a $\mathrm{r}$ S. Fractal analysis in chemistry and biology. An Introduction. Lambert Academic Publisher, 2010 (ISBN: 978-3-8433-7905-2).

25. J o n e s C.L., J e 1 i ne k H.F. Wavelet packet fractal analysis of neuronal morphology. Methods, 2001, 24(4): 347-358 (doi: 10.1006/meth.2001.1205).

26. Ristanović D., Nedeljkov V., S tefanović B.D., Milošević N.T., Grgu revi ć M., S tu li ć V. Fractal and nonfractal analysis of cell images: comparison and application to neuronal dendritic arborization. Biological Cybernetics, 2002, 87(4): 278-288 (doi: 10.1007/s00422-002-0342-1).

27. Sviridova O.V., Vorob'e v N.I., P o pov A.A. Materialy III Mezhdunarodnoi nauchnoi Internet-konferentsii «Biotekhnologiya. Vzglyad v budushchee» [Proc. III Int. online Conf. «Biotechnology. A look into the future»]. Kazan', 2014, 2: 102-106 (in Russ.).

28. S c h ro e d e r M. Fraktaly, khaos, stepennye zakony. Miniatyury iz beskonechnogo raya [Fractals, chaos, power laws: minutes from an infinite paradise]. Izhevsk, 2001 (ISBN 5-93972041-2) (in Russ.).

29. B o g a t y k h B.A. Fraktal'naya priroda zhivogo: sistemnoe issledovanie biologicheskoi evolyutsii $i$ prirody soznaniya [Fractal character of life: study of biological evolution and the consciousness]. Moscow, 2012 (ISBN 978-5-397-02429-7) (in Russ.). 
30. E z e ki e l S. Medical Image Segmintation using multifractal analysis. Proc. of the App. Informatics, 2003, 378: 220-224.

31. Lo pes R., B e t ro u i N. Fractal and multifractal analysis: a review. Medical Image Analysis, 2009, 13(4): 634-649 (doi: 10.1016/j.media.2009.05.003).

32. Seuront L. Fractals and multifractals in ecology and aquatic science. UK, CRC Press, 2009.

33. Takahashi T., Murat a T., N a rit a K., Hamada T., Kosaka H., O mori M., Takahashi K., Ki mura H., Yoshida H., Wad a Y. Multifractal analysis of deep white matter microstructural changes on MRI in relation to early-stage atherosclerosis. NeuroImage, 2006, 32(3): 1158-1166 (doi: 10.1016/j.neuroimage.2006.04.218).

34. Ti a n Y.-C., Y u Z.-G., Fidge C. Multifractal nature of network induced time delay in networked control systems. Physics Letters A, 2007, 361(1): 103-107 (doi: 10.1016/j.physleta.2006.09.046).

35. Y o u ng I.M., C r a w ford J.W. Interactions and self-organization in the soil-microbe complex. Science, 2004, 304: 1634-1637 (doi: 10.1126/science.1097394).

36. Crawford J.W., De a con L., Grinev D., Harris J.A., Ritz K., Singh B.K., Young I. Microbial diversity affects self-organization of the soil-microbe system with consequences for function. Journal the Royal Society Interface, 2012, 9: 1302-1310 (doi: 10.1098/rsif.2011.0679).

37. Vorob'ev N.I., Sviridova O.V., Patyka N.V., Dumova V.A., Mazirov M.A., $\mathrm{K}$ rug lov Yu.V. Materialy Mezhdunarodnoi konferentsii «Biodiagnostika v ekologicheskoi otsenke pochv $i$ sopredel'nykh sred» [Proc. Int. Conf. «Biotests in ecological assessment of soils and adjacent environments»]. Moscow, 2013: 38 (in Russ.).

38. Netrusov A.I., Kotova I.B. Mikrobiologiya [Microbiology]. Moscow, 2006 (in Russ.).

\section{Science Events \\ NEW APPROACHES AND CONCEPTS IN MICROBIOLOGY}

(27-30 June 2017, Heidelberg, Germany)

Organization: EMBO/EMBL Symposium

This symposium will cover a broad range of topics in prokaryotic biology, including antibiotic-related research, network biology, bacterial communities, cell biology, regulation \& signalling, pathogenesis and evolution. Emphasis will be placed on novel approaches that drive each field or have the potential to revolutionise future research in microbiology.

Information: http://www.globaleventslist.elsevier.com/events/2017/06/new-approaches-and-conceptsin-microbiology/ 